\title{
TRADITIONAL AUSTRALIAN MEDIA ORGANISATIONS ADOPTION OF THE WORLD WIDE WEB
}

\author{
DARREN BURDEN ${ }^{1}$, PHILIP JOYCE ${ }^{2}$ and JAMIE MUSTARD ${ }^{3}$ \\ ${ }^{\prime}$ IT Department, Fairfax Pty Ltd, Australia \\ ${ }^{2}$ School of Information Technology, Swinburne University of Technology, Australia \\ ${ }^{3}$ School of Management Information Systems, Deakin University, Australia
}

Abstract: The aim of this paper is it to identify whether Australian media companies moved online with a clear business model in mind or in an ad-hoc manner. Indepth interviews were conducted with four Internet media managers from two large Australian media organisations. All four had been involved in Web publishing from its early stages and had extensive knowledge of the development of Web publishing in the industry. The interviews focused on the period around the mid 1990's when the early development of the organisations' websites took place. We also review an analytical approach of examining narratives from research interviews developed by Davidson (Davidson 1997) and Mishler (Mishler1986a, 1986b).

\section{INTRODUCTION}

Information has been a commodity of large publishers and media organisations since the development of the first moving press in 1440. Such organizations are currently experiencing a revolution in the way information is handled, stored and disseminated. In the last 20 years there has been a new movement away from mechanical technologies to create goods to the buying and selling of information handled with electronic technologies. The rise of this information technology revolution - fuelled by the advances in 
communication and digital technologies - to disseminate and distribute data quickly and cheaply is changing the balance from large organisations to individuals.

Media organizations are of particular interest, as they are an industry that sells the basic material which information technology was spawned from, raw information or data. The information systems behind the media product are networks of digital data transmission. Telephones, Faxes, wire services, databases of old stories and computers to write the story on are the tools and services that media organisations use to create the final product: words, sound, vision. Media organisations have had a monopoly on information as the large capital needed to make your own paper, television or radio station (Smith 1980), but that is changing in the form of the WWW. The WWW has opened up an opportunity for potentially anyone to set up his or her own publishing company with very little capital. Web pages about your favorite hobby can be published and distributed across the globe in seconds, in what was once the domain of large publishers who had the capital to attempt such feats.

Currently, most Australian media organisations are providing some of their information product on the Web. There is an important distinction between an online retailer, who makes money from selling their goods online, and the media company that is giving away its goods, news and information, online. Even in the media industry there is a further distinction between publishers putting their narrowband content online and broadcasters putting their broadband content online. Broadcasters can't put all their TV shows on the Internet yet because of speed restrictions, but a newspaper company can, and do, put its journalists' stories online in text form.

From the outside it seems that many of the major publishers and broadcasters in Australia jumped on the WWW roller coaster, spending money on developing Web sites without any sound business justification. What is worse is that many of these businesses may have jumped onto the Web without any explicit information technology strategies, totally ignoring the possible impact of their new ventures on the organisation.

A report by Eric Meyer (Meyer 1995) for Newslink Associates in America was a strategic planning guide for online publishing by general circulation newspapers. Meyer addresses many of the issues and risks that newspapers needed to be aware of when moving into the new electronic media. This work is important because it could alleviate many of the fears and heal the burns that publishers perceived when they jumped onto the last 'new' electronic media, teletext and videotext, which were an expensive failure (Meyer 1995:1). It also attempts to show where online media will fit in with the newspaper businesses. 
This paper explores whether Australian WWW media sites were built with a clear business model or in an ad-hoc manner. In order to investigate this idea there needs to be an understanding of why media organisations moved online. In particular, did established Australian media organisations move online with a clear business model or in an ad-hoc manner and were the strategic intentions of moving online in-line with the businesses objectives?

The paper is organised as follows. In section 2 we examine the Australian media industry. Section 3 describes the analytical approach of examining narratives that was used during this research. The research design and participants in the study are described in Section 4. Lastly, the main results of the study and conclusions are given in Sections 5, 6 and 7.

\section{AUSTRALIAN MEDIA ORGANISATIONS}

The importance of the Internet as a new way of distributing information for large media groups has not been ignored. All the large media organisations in Australia have some type of investment in online business (Burden 2000:6). Some organisations have separate sites for each masthead (i.e., corporate areas) while others have a single portal for various mastheads in the company. What is not clear from viewing online sites is their overall strategy for the online world and how they see it cohabitating with the paper (Petre and Harrington 1996:17).

The Australian online sites are all free media. They're free in the sense of free-to-air television, which doesn't cost to view but is paid through some other means, usually advertising. In a traditional newspaper circulation contributes to $20 \%$ of the overall income while advertising and classifieds bring in the remaining 80\% (Meyer 1995:15). The New York Times Online originally had a general access fee but this was waived and consequently the number of visitors to the site doubled (Miller 1999). The traditional fee based transaction of newspapers is not used by any Australian media organisation. The only time some kind of fee may change hands is when a consumer wants to access a story stored in historical archives.

\subsection{The Evolution of the Media and the Impact of the WWW}

The distribution and control of information within media organizations have typically followed a mass medium system architecture, which is 
pyramid shape. Information comes into a point of news making or gathering and is distributed to a mass audience. The pyramid distribution of news not only applies to publishing, it is also relevant to television and radio news distribution as shown in figure 1 .

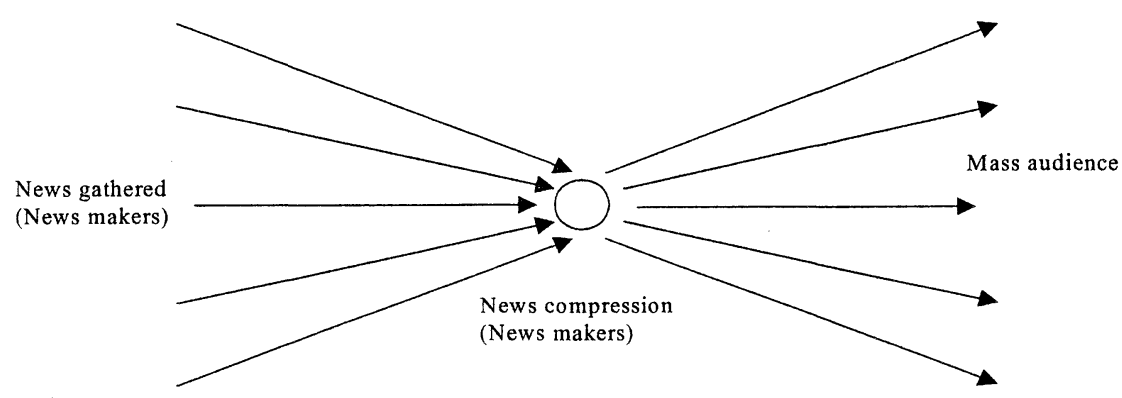

Figure 1. Mass media system architecture

The news gathered is the journalists, photographers, cameramen and wire feeds that are gathered by the news organisation at the news compression node. The news product distribution channel, whether it's television or newspaper, sends the same information to the mass audience or consumer (Newhagen and Levy 1998:11).

Internet based communication is distributed: changing the way information can be gathered and disseminated amongst consumers. The flow of information is no longer linear, but a complex network of sending and receiving nodes. Each node is a Web site, electronic bulletin board, email account or other Internet based tools, personal or organisationally controlled, that can have its own news or refer to news on other nodes within the network (Newhagen and Levy 1998:11). The Internet has provided a vehicle that separates the production and control from the newsmakers to the consumers, which is represented by the sender/receiver nodes capable of moving information over the architecture (Newhagen and Levy 1998:16). The interactivity of the architecture has allowed this change in news distribution. 
Wide Web

\subsection{Strategic Usage of the WWW by Australian Media Organisations}

The Australian audience regularly using the Internet is greater than the audited circulation of The Sydney Morning Herald and The Australian (Petre and Harrington 1996:124). From June 1999 a Roy Morgan Research poll indicated that $47 \%$ of Australians aged 14 or greater had accessed the Internet and $35 \%$ of those people accessed the Internet at least monthly (Research 2000). The Australian Bureau of Statistics indicate there has been steady growth in Internet usage in Australia, between 1998 and 1999 there was a $27 \%$ increase in home Internet access alone (ABS 1999). Moreover, the use of the Internet by professionals and managers is between $64 \%$ and $75 \%$ (Research 2000). This audience has become an opportunity for media companies and other companies to capture new and untapped markets.

The rush to capture new markets has however led to confusion and unreal expectations due to the lack of Web understanding (Schulman and Smith 1997:2). The strategic advantage that the WWW has opened up includes the opportunity for business to improve their "processes and customer interfaces to create a sustainable, competitive advantage" (Lawrence et al. 1998:8). According to Porter the Internet is going to affect every company in some way. Every company is full of information systems and those information systems reside in virtually every activity in the value chain, it's clear that the Internet is going to affect every company (Porter 1999). However, Porter points out that the effect is not going to be strategic or transformational on companies that have a physical product that have to be serviced. Although the WWW can be used to streamline parts of the value chain of these companies, the information-based companies (such as the media organizations) will be the most affected by the WWW technology.

The industries where the Internet is likely to be transformational are industries that are the most obvious cases, where what you are providing is the service or basic information itself - something like stockbrokerage or making a market like auctions or providing digital goods that are actually basic information goods (Porter 1999).

Clearly, any strategy developed by an organisation must encapsulate the current trends and technology used not only within the organisation but what is being used within the industry and in other industries. Some industries will be affected more than others, however, any well-developed strategy needs to be focused on providing services and goods that their consumers want and need. 


\section{EVALUATION OF THE AUSTRALIAN MEDIA ORGANISATIONS}

The objective of this study is to gain an understanding into the adoption and implementation of Internet sites by Australian media organization that took place during the mid 1990's, as clearly started in the Introduction. Of particular interest was whether traditional media vendors followed any business models or assessed the strategic impact their move onto the WWW would have on their businesses. A major consideration of this work was the limited number of media organisations within Australia. Each of these media organisations have considerable synergies and a number of key employees have worked in many of these Australia media organisations. Moreover, there were a limited number of key employees from that period still in the industry. Information about this period would come from interviewing these people. In order to effectively capture this period of time it was decided to adopt a methodological approach to analyse the interview narratives that has previously been used by Davidson in information systems research (Davidson 1997). In the remainder of this section we review Davidson's approach drawing primarily on the work done by Davidson (Davidson 1997) and Mishler (Mishler 1986a 1986b).

\subsection{Analysing narratives: a methodological approach}

Davidson proposed a methodological approach for analysing interview narratives and applied it within the information systems field (Davidson 1997). This structural analysis tool is based on the theories of social scientist Mishler, and his theories of narrative analysis in Research Interviewing: context and narrative (Mishler 1986b) and The analysis of interviewsnarratives (Mishler 1986a). It's a three-phased examination of structure, meaning and interaction context, which we cover in the next three subsections.

\begin{tabular}{|l|l|}
\hline Category & Description \\
\hline Narrator's perspective & $\begin{array}{l}\text { Segments or use of language (e.g., "I" or "we" versus "they") } \\
\text { in which the narrator reveals his or her perspective on events in } \\
\text { the narrative. }\end{array}$ \\
\hline $\begin{array}{l}\text { Orientation/contextual } \\
\text { descriptions }\end{array}$ & $\begin{array}{l}\text { Segments in which the narrator provides contextual } \\
\text { information which does not contribute to the movement of } \\
\text { action through time. These are not always present. }\end{array}$ \\
\hline Actors & $\begin{array}{l}\text { Segments or use of language (e.g., "I" or "we" versus "they") } \\
\text { which indicate who carried out actions or contributed to events } \\
\text { depicted in the narrative. }\end{array}$ \\
\hline Problematic situation & Segments in which the narrator describes his of her perceptions \\
\hline
\end{tabular}


Wide Web

\begin{tabular}{|l|l|}
\hline & $\begin{array}{l}\text { of the noncanonical or exceptional circumstances which } \\
\text { motivates actions described in the narrative. }\end{array}$ \\
\hline Goal/problem solution & $\begin{array}{l}\text { Segments in which the narrator describes his or her perceptions } \\
\text { of how the problematic situation could be or was resolved. }\end{array}$ \\
\hline Actions and events & $\begin{array}{l}\text { Narrative clauses segments: } \\
\text { Actions are activities that occur during the time span of the } \\
\text { narrative that have a strict temporal sequencing. } \\
\text { Past actions or flashbacks serve as orientation clauses. } \\
\text { Events are recognised changes in state, such as completion of } \\
\text { an activity or arriving at a decision point. }\end{array}$ \\
\hline Outcomes & $\begin{array}{l}\text { Segments in which the narrator describes the perceived } \\
\text { outcome of actions and events, such as resolution of the } \\
\text { problematic situation by achieving the goal. }\end{array}$ \\
\hline
\end{tabular}

Table 1. Classification categories for narrative segments (Davidson 1997:130)

\subsection{Structure Analysis}

The first phase of structural analysis involves identifying the components of the interviewees' narrative accounts or descriptions. The narrative accounts are divided into segments of partial, complete or strings of sentences that contain distinctive information. The distinctive information is narrator's perspective, orientation/contextual information, actors, problematic situation, goal/problem solution, actions and events and outcomes. All these areas are outlined by Davidson (1997) and reproduced in Table 1.

\subsection{Meaning: Global, Local, Themal}

The second part of the analysis involves coherence relations. This attempts to reveal implicit meaning within the context of the narrative. The three general coherence relations that impart a form of unity into a narrative text are:

- Global coherence, which relates to the speaker's overall plan or intent for the narrative;

- Local coherence, which refers to the function of an utterance within the immediate text segment; and

- Themal coherence, which suggests the narrator's assumptions, beliefs, and goals that reoccur throughout the narrative. (Davidson 1997:126) 


\subsection{Interaction context}

This last step attempts to assess the impact the researcher/interviewer had on the interviewee/participant during the interview. Davidson (Davidson 1997) drew on Mishler's (Mishler 1986b) suggestions that "narratives are a joint production of interviewer and interviewee which reflects ongoing shifts in the reciprocal dual roles of interviewer/interviewee and listener/narrator" (Davidson 1997:126). Mishler notes that the interviewer's role in the production of narratives has largely been ignored (Mishler 1986a, Mishler 1986b). At this point the interviewer describes their relationship with the interviewee and how this may have reflected in the answers that were finally given. The interaction context is described before the two main narratives are analysed. This is due to both research objectives were explored in the one interview.

\section{RESEARCH DESIGN}

In Australia most major media organisations are located in Melbourne and Sydney. Indeed, these organisations are amongst the largest stocks listed on the Australian Stock Exchange. With the growing use of information technology, especially in electronic commerce and the Internet, suitably skilled employees are now able to move between organisations and industries. Employees in Australian Media organisations are no exception. This research was mindful of employees moving not only within the Australian media organisations but also to unrelated industries. This made the selection of suitable interviewees that were prominent in the early development of the media organisations web presence difficult. Eventually, four key industry leaders from two of the largest media organisations were selected and requested to participant in the research. Of the four participants only one was still employed by the same media organisation. The other three were still in the Internet industry but they were not in the 'traditional' media industry anymore.

The data collection involved an interview with each of the four participants and was retrospective and semi-structured. Three of the interviews were face-to-face and one participant was interviewed over the phone. Full transcripts of the relevant data being analysed in this research can be found in Burden (2000). The questions revolved around questions on:

- Background information about each person;

- Was there a champion in upper-management?

- Did established Australian media organisations move online with a clear business model or in an ad-hoc manner? 
- Were the strategic intentions of moving online in-line with the business objectives of the company?

- What was the revenue plan and what was the site providing to the core business?

The following section is a basic description of the companies and the participants within those companies. The ethical approval of this research requires the identity of the participants and their organisations not to be disclosed and are simply referenced as participant A, participant B, etc., and Media Organisation A, Media Organisation B. Each participant is referred to as "she" or "her" in the following descriptions.

\subsection{Selected Organisations}

Media Company A is a large Australian publisher that has had an online presence since early 1995. The company has metropolitan and country publications in Victoria and New South Wales. The company has also created a separate Internet company although this was not realised until the late 1990s. Participant B was involved with the first implementation of a Web site for Media Company A. Participant B's title was electronic publishing and information services (library) manager, this included CDROMS and other digital services; Internet responsibilities were a minor part in this role. Participant A took over from participant B in about 1996. The role was a combined IT manager and online publishing manager role for Masthead A1, which Participant A did until 1999. The major differences between these two people are Participant $\mathrm{A}$ had an editorial background and Participant $\mathrm{B}$ had a librarian background.

Media Company B is also a large Australian publisher that had an online presence since 1995. The company has metropolitan and country publications Australia wide. The organisation has had a separate multimedia company since it's Internet beginnings, but was originally focused with CDROMS. This was later changed to an Internet focus. Participant $\mathrm{C}$ was an editorial manager for Masthead B1, who was involved with the first Internet site for Media Company B, a few years later. Participant D came in as editor of Masthead B1's Web site in 1996, later moving into the separate Internet business of Media Company B in 1998. Participant D is still involved with Media Company B.

\subsection{Interaction context}

A section of the narrative analysis is the interaction context that defines the interaction between the interviewer and interviewee. This helps identify 
how the interviewer may have shaped the interview in the initial approach and the assumptions of shared knowledge.

\subsubsection{Participant A Interview (Media Company A)}

The context was a formal interview conducted with participant $\mathrm{A}$ in her work office. The interviewer had contacted the participant via email and then by phone. The interviewer had met the participant before this interview and knew some mutual friends in the media industry. The interviewer used these relationships to build a rapport with the interviewee, enhancing the likelyhood of participation. The interviewee and interviewer had some similarities in professional background and this also helped build a rapport.

\subsubsection{Participant B Interview (Media Company A)}

The interviewer initially contacted the participant via email and then by phone. The interview was conducted in a meeting room in Participant B's place of business. Prior to the interview the researcher and the participant had a coffee together to discuss what the research was about and professional work. At this point we discovered mutual colleagues. The interviewee used assumed knowledge during the interview, not describing some people and positions during the interview. While interviewing the researcher tried to keep the questions as open as possible but keeping them within the bounds of the topic of interest.

\subsubsection{Participant C Interview (Media Company B)}

The interviewer contacted the participant via email and then talked to her on the phone. The first time the researcher and participant spoke to each other the phone conversation went for about 20 minutes and covered topics that were peripheral to the research topics. The formal interview took place in the participant's office.

\subsubsection{Participant D Interview (Media Company B)}

The interviewer contacted the participant via email and then talked to the participant on the phone. From the first point of contact until the interview was conducted there was about a two-month lag as the participant and interviewee kept missing each other's suggested meeting times. After failing to be able to meet face-to-face a phone interview was decided to be the best way of conducting the interview. This interview didn't have the preliminary and post 'small talk' of the other interviews. The researcher felt a little less 
involved with this interview compared to the three prior interviews. This was the quickest interview of the four.

\section{INDIVIDUAL NARRATIVE ACCOUNT: PARTICIPANT A}

Analysing narratives is a voluminous task and text may contain many interwoven and partial stories. Therefore, we have selected only one of the participants and one of the research questions from this study to present the methodological approach, as outlined by Davidson, in depth. The full analysis of all participants and all research questions can be found in Burden (2000). In the following section we analyse the narratives of Participant A that were concerned with whether Media Company A moved online with a clear business model or in an ad-hoc manner.

\subsection{Structure Analysis}

The structural analysis focuses on the narrative clauses and creation of an abstract of the plot sequence through which the narrator organises her explanation for her and others' actions. The results of this analysis are shown in table 2 and all references refer to Burden (2000). This revealed:

- recognition that the Web was going to emerge as something important;

- preliminary research into the emerging industry; and

- the selection of a course of action.

In the first problem solving sequence there is a recognition that "something was going to happen to transfer a lot of information, distribution and publishing to electronic media". Other signs of the importance of the Web came from an advertising manager who "recognised very early that his customers were taking a big interest in moving some of their activities online," and this had all been recognised by the librarians first. Although there had been some Internet activity in Media Company A, participant A and 'others' were actively looking at what other people were doing by traveling overseas. There had also been some other multimedia projects that had been in the pipeline before the business interest in the Web heated up. The participant had also done some research in classified sites and especially real-estate sites; "we saw a couple of examples like that early property real estate site." The selection of a course of action was created from a classifieds bent, "we looked at that and thought, well, real estate is going to be the first one to go off because that looked as if it was a working model." The creation 
of any clear business model was complicated, as there were not many other models to go off either overseas, or in Australia. In fact participant A found that when she went overseas her understanding of what they were doing in her company was in "advance" of people overseas. The move online was hampered by a number of factors including not enough people or money and lack of editorial involvement, which is related to a lack of enthusiasm shown by people "you needed to work with."

\begin{tabular}{|c|c|}
\hline $\begin{array}{l}\text { Narrator's } \\
\text { abstract }\end{array}$ & $\begin{array}{l}\text { "I don't know whether they actually did, well ... I suppose there was a } \\
\text { couple of stages" ( } 87: 39-40) \text {. }\end{array}$ \\
\hline $\begin{array}{l}\text { Narrator's } \\
\text { perspective }\end{array}$ & $\begin{array}{l}\text { "So we were pro-active about it and some were not." (p87:12-13) } \\
\text { "we also looked at next generation advertising systems which } \\
\text { anticipated some Internet activity" (p87:68-69) } \\
\text { "We found that when we went overseas that often our understanding of } \\
\text { what we were doing and what we needed to do was in advance to some } \\
\text { of the people who we spoke to over there." (p87:78-82) }\end{array}$ \\
\hline $\begin{array}{l}\text { Orientation/ } \\
\text { contextual } \\
\text { descriptions }\end{array}$ & $\begin{array}{l}\text { "to a certain degree it was the champions of electronic media who } \\
\text { persuaded the company to give them support ..." (p87:13-16) } \\
\text { "the librarians were the first to see this happening if you like." (p87:18- } \\
\text { 20) } \\
\text { "Media Company A in Sydney were very, very slow. Although that's } \\
\text { not what they will tell you." (p87:34-36) } \\
\text { "Basically it was planned outside the core organisation" (p87:48-49) } \\
\text { "Newspapers overseas were very slow too, newspapers in the States } \\
\text { were among the last people to wake up to the fact that the Internet was } \\
\text { going to be important." (p87:70-73) } \\
\text { "I've never thought that publishing newspapers online in newspaper } \\
\text { form was a long term strategy anyway." (p87:93-95) }\end{array}$ \\
\hline Actors & $\begin{array}{l}\text { Person AR - Participant B, Library Manager of Masthead A1 } \\
\text { (p87:16,47,49) } \\
\text { Person AI - Library Manager of Masthead A2 (p87:17) } \\
\text { Person AU - Advertising Manager, Masthead A1 (p87:29,67) }\end{array}$ \\
\hline $\begin{array}{l}\text { Problematic } \\
\text { situation }\end{array}$ & $\begin{array}{l}\text { "I think their reasons would have been that if something was going to } \\
\text { happen to transfer a lot of information, distribution and publishing to } \\
\text { electronic media then Media Company A had to at least make sure it } \\
\text { was in there and it understood what was happening. Purely as a risk } \\
\text { management exercise." (p87:6-12) } \\
\text { "Under budgeted and user resourced for a lot of the time." (p87:25-26) } \\
\text { "There was not much interest or enthusiasm shown by people who you } \\
\text { needed to work with." (p87:26-28) } \\
\text { "the advertising manager was one person who recognised very early that } \\
\text { his customers were taking a big interest in moving some of their } \\
\text { activities online ..." (p87:29-32) } \\
\text { "Person AR used to publish Masthead A1 Web site without much } \\
\text { involvement from anybody in editorial at all." (p87:49-51) } \\
\text { "Nobody in Australia was doing anything." (p87:65) } \\
\text { "There wasn't many models for newspapers to look at in terms of what } \\
\text { the Internet was going to mean for them." (p87:76-78) }\end{array}$ \\
\hline
\end{tabular}


Wide Web

\begin{tabular}{|l|l|}
\hline $\begin{array}{l}\text { Goal/problem } \\
\text { solution }\end{array}$ & $\begin{array}{l}\text { Librarians began the sites as they saw the Importance of the Internet to } \\
\text { the company, they got the initial support (p87:13-21) } \\
\text { "we had a contractor in to build the Web site." (p87:56-57) }\end{array}$ \\
\hline $\begin{array}{l}\text { Actions and } \\
\text { events }\end{array}$ & $\begin{array}{l}\text { Mentions two failed ventures that his company was involved in (p87:40- } \\
47) \\
\text { Talks about the contractor building the news Web site but points out the } \\
\text { core of the contractors work was the IT jobs (p87:56-59) } \\
\text { Looked at real estate as the next big thing on the Web - as far as online } \\
\text { classifieds go - but was wrong as employment was (p87:86-90) } \\
\text { "A few of us from Melbourne did travel overseas, I and a colleague } \\
\text { went over twice basically to an expo" (p87:56-68) }\end{array}$ \\
\hline Outcomes & $\begin{array}{l}\text { "we looked at that and thought, well, real estate is going to be the first } \\
\text { one to go off because that looked as if it was a working model" (p87:86- } \\
89) \\
\text { "I suppose we looked at very basic early Internet classifieds and though } \\
\text { that was pretty much what we had to do." (p87:90-92) }\end{array}$ \\
\hline
\end{tabular}

Table 2. Participant A - Did Australian media organisations move online with a clear business model or in ad-hoc manner?

\subsection{Meaning: Local, Global and Themal Coherence in the Narrative of Participant $A$}

In the analysis of meaning, the local, global and themal coherence of segments in the narrative of Participant A was considered. The researcher asked "how did Media Company A plan the move onto the World Wide Web?" (p87:37-38) she answered "I don't know whether they actually did. Well I suppose there was a couple of stages" (p87:39-40). This statement has local coherence as it introduces the events leading up to the company's move onto the Web. At the same time it is global as it serves as the abstract of the participants group of answers. Although coming in about a third of the way through the group of questions it sets the stage for participant grouped answers. At the third level, themal coherence, it describes the lack of an early global plan for the Media Company and its foray onto the WWW, save for small stages like the concentration on classifieds (p87:85-92), advertising (p87:29-32) or editorial development (p87:59-51).

The segment "there weren't many models for newspapers to look at in terms of what the Internet was going to mean for them" (p87:76-78) has global coherence. It is almost an excuse for the newspaper not to have a 'business model' as nobody else did. The infancy of the industry is almost a reason for lack of business plans as the participant says "newspapers overseas were very slow too" (p87:70-71) or 'our' meaning people within Media Company A had a greater understanding of what they were doing 
compared to colleagues overseas (p87:78-82). These bits of information deflect the enquiries about their business plans to a third party.

The statement "Media Company A in Sydney were very, very slow. Although that's not what they will tell you" (p87:34-36), has a themal coherence. This implies a separation in the company between the cities, and a lack of trust is also evident when the participant warns the researcher to be wary of lies when talking to people involved with Media Company A in Sydney. As far the segments relation to the business model question it shows that there was a separation of planning between the Sydney and Melbourne arms of Media Company A. At this point it must be noted that the researcher only talked to Melbourne based participants from Media Company A.

\section{A COMPARISON OF NARRATIVES}

A comparison of the different narratives between participants and companies is made regarding the manner in which the move online was made.

\subsection{Media Company A}

Participants $\mathrm{A}$ and $\mathrm{B}$ constructed the origins of the Web site and developed basis of a business plan. However, a number of differences did exist in solving the problem. In both cases the participants recognised that Web publishing was something that was going to be very important to the company. Participant A accredits this recognition to the librarian and the advertising manager at the time. Participant B is the librarian that Participant A indicates, she recognised the importance of the Web and consequently she personalises the beginnings as something she pushed, as someone who understood the medium and its purpose (p88:2-3,42-43).

At the next stage Participant $\mathrm{A}$ describes preliminary research that involved overseas trips, which in most cases showed her that in many cases Company A's understanding of the Web was in advance of other people in the industry. Participant B on the other hand is more concerned about the problems involved with creating a Web site, and the way she created solutions. Part of this solution was to show people the technology and how it could be used. She concentrates on the building of her knowledge, with information exchanges with experts from the United States. She also highlights the things that weren't available to her like sufficient human and dollar resources.

Participant A, who had come from editorial background had strong views on putting news online, "I've never thought that publishing newspapers 
online in newspaper form was a long term strategy" (p87:93-94), and was very focused on the classifieds side of the Internet business (p87:85-92). Participant $B$ has a librarian background and was involved in very early use of the Internet in Media Company A was more focused on getting something online, and seemed more editorial focused. Interestingly Participant B worked very hard in the editorial area, by communicating with experts in the field (p87:49-53) after realising that they had a deficiency in the understanding of editorial matters ( $\mathrm{p} 87: 39-40)$.

\subsection{Media Company B}

These narratives are similar in nature to company A. In both cases the narrative plot identifies a beginning that indicates people within Media Company B realised a Web presence was needed. Participant $\mathrm{C}$ personalised the sequence more than Participant D, because Participant $C$ was directly involved with the first version of Web publishing within the company, Participant $\mathrm{D}$ got involved later. Participant $\mathrm{C}$ describes many of the problems with launching the site including no support and even an instance of voiced opposition (p90:13-16). Her largest focus was on the issue of copyright and how that made it more difficult to create a Web site as she had to rewrite copy from the newspaper or else the Union, which she doesn't support, would cause a strike within another organisation.

Participant D doesn't mention the copyright issue. She concentrates on the lack of monetary and technical support available (p92:17-22), as well as saying the Internet within the newspaper industry was "perceived more as a threat than an opportunity" (p92:25-26). Participant C also mentions budget problems with the implementation of the site (p92:93). When describing the Web site implementation, Participant D mentions that it was a "defensive strategy" (p92:4-7) which had a "hobbyist kind of approach" as it could disappear like "CB radio" (p92:41-43). Participant C segment of narrative about going head-to-head with Publisher $\mathrm{C}$ and Media Company A, who were already online, as well as the segment about stopping the white-anting of their classifieds market is a description of the defensive move online.

\subsection{Comparison of Media Company A and B}

Media Company B initial plan seemed to be in response to protecting their market or hedging their bets. In contrast Media Company A had a vague notion of the company having to be online, mostly driven by people like Participant A who could see the potential of the Web site to deliver information. All participants cited lack of resources, monetary, technical and 
even knowledge base, as problems with the initial implementation of the websites. Participant A and D, who were involved with the websites after Participants $\mathrm{B}$ and $\mathrm{C}$ respectively, were less personally involved with the implementation.

The planning of the websites wasn't a clear-cut document that was created and distributed amongst the Media Company, although participant D says there would have been 'something' like a plan circulated. Both companies created ad-hoc plans to begin with and there was no specific moment in any of the narratives that clearly identified the creation of a starting plan. In describing the situation in Media Company B, Participant D mentions "I couldn't grandeur this by saying we had a grand plan or vision from the start" (p92:33-37). Participant C explicitly states there was no clear planning until the Atlanta Olympics in 1996, "the whole 18 months, two years before then was very ad-hoc" (p88:65-66).

\section{CONCLUSION}

There was no official strategy, only a feeling that the companies needed to move online to protect their markets in classifieds and news disseminators. No participant was able to define a single clear plan in his or her approach to moving online as an Australian Media Organisation. Instead, they describe what types of influences made them shape a Web site. A typical sentiment inferred by Participant $B$ defines the Web site as something that is born out of multiple fronts. There were ad-hoc business plans that sprang up from other business units within the companies. Working with people who understand where you are going to people who are threatened by the Internet, "none of these things are linear." In using the narrative approach outlined in Davidson 1997, we have been able to clearly identify the information contained in the narratives of the interviews.

\section{REFERENCES}

ABS (1999) Use of the Internet by households (Australian Bureau of Statistics, August, 8147.0)

Burden, D. (2000) Adoption of the World Wide Web by Traditional Australian Media Vendors (Thesis), Deakin University, School of Management Information Systems.

Davidson, E.J. (1997) Examining Project History Narratives: An analytic approach, in: A.S. Lee, J. Lawrence, E., Corbitt, B., Tidwell, A., Fisher, J.-a. \& Lawrence, J.R. (1998) Internet commerce: Digital models for business (Brisbane, John Wiley \& Sons Australia, Ltd).

Meyer, E. (1995) Tomorrow's news today (Pewaukee, News Link Associates). 
Miller, S.C. (1999) Personal communications via email

Mishler, E.G. (1986a) The analysis of interviews-narratives, in: T.R. Sarbin (Ed) Narrative Psychology: The storied nature of human conduct (Londo, Praeger).

Mishler, E.G. (1986b) Research Interviewing: context and narrative (London, Harvard University Press).

Newhagen, J. and Levy, M. (1998) The future of journalism in a distributed communication architecture, (London, Lawerence Erlbaum Associates).

Petre, D. and Harrington, D. (1996) The clever country? Australia's digital future (Sydney, Pan MacMillian Australia).

Porter, M. (1999) The Net Won't Transform Everything, [Internet]. Inter@ctive Week. Available: http://www.zdnet.com/intweek/stories/news/0,4164,2381095,00.html [1 July 2000]

Research, Roy Morgan. (2000) Roy Morgan Research: Discover your edge, [Internet]. Roy Morgan Research. Available: http://www.roymorgan.com.au/ [July 12000$]$

Schulman, M.A. \& Smith, R. (1997) The Internet strategic plan (Brisbane, Wiley Computer Publishing).

Smith, A. (1980) Goodbye Gutenberg: The Newspaper Revolution of the 1980s (Oxford, Oxford University Press). 